\title{
Glomerular Localization of Interleukin-6 Suppressed by Steroid Mini-pulse Therapy in an IgA Nephropathy Patient
}

\author{
Yoshihiko Taniguchi, Noriaki Yorioka, Hiroaki Oda, Sayuri OKushin, \\ Yoji NishidA, Michio Yamakido and Takashi TAGUCHI*
}

\begin{abstract}
A 16-year-old female with IgA nephropathy harboring histologically active lesions was treated with steroid mini-pulse therapy. Immunohistochemical examination revealed a diffuse distribution of interleukin-6 (IL-6) in the renal biopsy tissue. After treatment, her clinical factors and renal function improved, and renal biopsy showed reduced histological lesions and disappearance of the IL-6 distribution. Immunohistological studies of cytokines, such as IL-6, may be useful for evaluating the therapeutic effects in IgA nephropathy.
\end{abstract}

(Internal Medicine 34: 1181-1185, 1995)

Key words: immunohistochemistry, cytokines, steroid therapy

\section{Introduction}

IgA nephropathy (1) does not have the good long-term prognosis, as previously thought (2). Anticoagulants, antiplatelet agents (3), steroids, and immunosuppressants (4) have been used extensively to treat IgA nephropathy, but no consensus on their efficacy has been reached.

The present study found that steroid mini-pulse therapy had excellent efficacy in a patient with IgA nephropathy as shown by histological improvement and the disappearance of interleukin-6 (IL-6) in the glomeruli. Localized observation of IL-6 was useful for the evaluation of therapeutic effects in IgA nephropathy.

\section{Case Report}

A 16-year-old Japanese female was discovered to have occult hematuria during a school health examination in April 1991. She was subsequently examined by a local physician, but no abnormalities were found in the urine and consequently no treatment was given. A school health examination in April 1993 noted occult hematuria with proteinuria. She underwent an examination at the Department of Urology of Asa Municipal Hospital in July 1993. Her urinary protein was 2+ and many erythrocytes were found in the urinary sediment. Since no other urological abnormalities were found, IgA nephropathy was suspected. She was admitted to our hospital for a renal biopsy on August 18. Nothing noteworthy was found in her medical history or family history.

Physical examination on admission found she was $160.8 \mathrm{~cm}$ tall and weighed $57.6 \mathrm{~kg}$. Her blood pressure was normal (120/ $80 \mathrm{mmHg}$ ). There were no external abnormalities such as purpura, and no edema was evident. There were no abnormal neurological findings. Laboratory tests revealed albumin to be \pm and occult hematuria was $3+$, and many erythrocytes were found in the urinary sediment. Her total daily protein excretion was $0.14 \mathrm{~g} /$ day. No abnormalities were found by peripheral blood tests, coagulation tests or blood chemistry. Serological examinations showed elevated antinuclear antibody and serum IgA levels, but the complement showed no decrease. Renal function tests revealed no particular abnormalities: BUN was $11 \mathrm{mg} / \mathrm{dl}$, serum creatinine $0.67 \mathrm{mg} / \mathrm{dl}$, and 24-hour creatinine clearance $111.3 \mathrm{ml} / \mathrm{min}$ (Table 1). Biopsy of the renal tissue showed segmental active proliferative changes in the mesangial area, and segmental sclerosis and fusion with Bowman's capsule. Small cellular crescents were present in 3 of 35 glomeruli, and fibro-cellular crescents were present in 4 of 35 glomeruli (Fig. 1A). Fluorescent antibody staining mainly showed $\operatorname{Ig} \mathrm{A}$ deposits in the mesangial region (Fig. 2A). Deposits of C3 and fibrinogen were also observed. Electron microscopy showed electron dense deposits in the mesangial area (Fig. 3A). Based on these findings, histologically active, moderate IgA nephropathy was diagnosed. An immunohistochemical study using frozen sections revealed IL-6 to be diffusely distributed in the

From the Second Department of Internal Medicine, Hiroshima University School of Medicine, Hiroshima and *the Second Department of Pathology, Nagasaki University School of Medicine, Nagasaki

Received for publication April 11, 1995; Accepted for publication September 5, 1995

Reprint requests should be addressed to Dr. Yoshihiko Taniguchi, the Second Department of Internal Medicine, Hiroshima University School of Medicine, 12-3 Kasumi, Minami-ku, Hiroshima 734 
Table 1. Laboratory Data on First Admission

\begin{tabular}{|c|c|c|c|c|c|}
\hline \multicolumn{2}{|l|}{ Urinalysis } & \multicolumn{4}{|l|}{ Blood chemical exam. } \\
\hline Colour & Yellow & Total bilirubin & $1.0 \mathrm{mg} / \mathrm{dl}$ & Immunoglobulin $\mathrm{G}$ & $1,420 \mathrm{mg} / \mathrm{dl}$ \\
\hline Turbidity & Clear & Direct bilirubin & $0.3 \mathrm{mg} / \mathrm{dl}$ & Immunoglobulin A & $405 \mathrm{mg} / \mathrm{dl}$ \\
\hline $\mathrm{pH}$ & 7.0 & Aspartate aminotransf & ferase $\quad 15 \mathrm{U} / l$ & Immunoglobulin $\mathrm{M}$ & $301 \mathrm{mg} / \mathrm{dl}$ \\
\hline Albumin & \pm & Lactate dehydrogenas & $375 \mathrm{U} / l$ & Complement 4 & $24 \mathrm{mg} / \mathrm{dl}$ \\
\hline Occult & $3+$ & Cholinesterase & $343 \mathrm{U} / l$ & Serum complement & $35 \mathrm{U} / \mathrm{ml}$ \\
\hline Sediment & & $\gamma$-Glutamyltranspeptid & $5 \mathrm{U} / l$ & Blood urea nitrogen & $11 \mathrm{mg} / \mathrm{dl}$ \\
\hline Red blood cell & Many/HPF & Total protein & $7.6 \mathrm{~g} / \mathrm{dl}$ & Creatinine & $0.67 \mathrm{mg} / \mathrm{dl}$ \\
\hline White blood cell & $0-1 / \mathrm{HPF}$ & Albumin & $4.7 \mathrm{~g} / \mathrm{dl}(66.9 \%)$ & Uric acid & $4.0 \mathrm{mg} / \mathrm{dl}$ \\
\hline Cast & - & $\alpha_{1}$-globulin & $2.2 \%$ & Serum $-\beta_{2}$ microglobulin & $1.36 \mu \mathrm{g} / \mathrm{ml}$ \\
\hline Crystal & - & $\alpha_{2}$-globulin & $9.4 \%$ & Urinary $-\beta_{2}$ microglobulin & $0.29 \mu \mathrm{g} / \mathrm{ml}$ \\
\hline \multicolumn{2}{|c|}{ Total daily urinary protein $0.14 \mathrm{~g} /$ day } & $\beta$-globulin & $7.9 \%$ & Creatinine clearance ( 2 hours) & $112.3 \mathrm{ml} / \mathrm{min}$ \\
\hline Red blood cell count & $466 \times 10^{4} / \mu 1$ & Triglycerides & $76 \mathrm{mg} / \mathrm{dl}$ & Renal blood flow & $1,076 \mathrm{ml} / \mathrm{min}$ \\
\hline Hemoglobin & $14.5 \mathrm{~g} / \mathrm{dl}$ & $\mathrm{Na}$ & $143 \mathrm{mEq} / \mathrm{l}$ & Phenolsulfonphthalein test $15 \mathrm{mi}$ & linute $\quad 40 \%$ \\
\hline Hematocrit & $40.8 \%$ & $\mathrm{~K}$ & $3.9 \mathrm{mEq} / \mathrm{l}$ & Fishberg concentration test & 1.030 \\
\hline \multirow[t]{2}{*}{ Platelet } & $19.2 \times 10^{4} / \mu 1$ & $\mathrm{Cl}$ & $106 \mathrm{mEq} / \mathrm{l}$ & & \\
\hline & & $\mathrm{Ca}$ & $4.6 \mathrm{mEq} / \mathrm{l}$ & Chest X-P & $\mathrm{CTR}=44.4 \%$ \\
\hline Coagulation exam. & & $\mathrm{P}$ & $3.3 \mathrm{mg} / \mathrm{dl}$ & & \\
\hline Prothrombin activity & $105 \%$ & Serum exam. & & Intravenous pyelography & n normal limit \\
\hline aPTT & $42.1 \mathrm{sec}$ & $\mathrm{C}$ reactive protein & $0.3>\mathrm{mg} / \mathrm{dl}$ & & \\
\hline Fibrinogen & $286 \mathrm{mg} / \mathrm{dl}$ & Antistreptolysin $\mathrm{O}$ & $56 \mathrm{IU} / \mathrm{ml}$ & & \\
\hline s-FDP & $1.16 \mu \mathrm{g} / \mathrm{ml}$ & Antistreptokinase & $\times 80$ & & \\
\hline u-FDP & $0.1>\mu \mathrm{g} / \mathrm{ml}$ & Rheumatoid factor & $6.0>\mathrm{IU} / \mathrm{ml}$ & & \\
\hline
\end{tabular}

s-FDP: serum-Fibrin/Fibrinogen degradation products, u-FDP: urinary-Fibrin/Fibrinogen degradation products, aPTT: Activated partial thromboplastin time.

mesangium area (Fig. 4A). However, platelet derived growth factor (PDGF)-A and -B were not observed.

The treatment regimen consisted of oral administration of 30 $\mathrm{mg} /$ day of prednisolone and $300 \mathrm{mg} /$ day of dilazep dihydrochloride, started immediately after the first renal biopsy. Steroid mini-pulse therapy was also performed, using $500 \mathrm{mg}$ /day of methylprednisolone, because of the lower risk of various side effects such as infection and the same efficacy as $1.0 \mathrm{~g} /$ day of methylprednisolone. Complete consent was obtained from the patient and her parents prior to the start of the therapy. The active lesions had disappeared at the second renal biopsy on November 17, 1993, and the dose of prednisolone was gradually reduced. Clinical factors and BUN and serum creatinine improved slightly during treatment, and the proteinuria and occult hematuria showed improvement. Therefore, a third renal biopsy was performed on July 27, 1994 to further evaluate the treatment effects. The renal tissue contained only very slight proliferation of mesangial cells and matrix, crescents in only one of 17 glomeruli, and marked histological improvement was observed (Fig. 1B). Fluorescent antibody staining showed a few IgA deposits in the mesangial region (Fig. 2B), and electron microscopy identified a few electron dense deposits in the mesangial area (Fig. 3B). The diffuse distribution of IL-6 seen at the first renal biopsy had disappearded (Fig. 4B).

\section{Discussion}

In recent years, steroid therapy has been widely used for patients with histologically active, progressive IgA nephropathy and moderate or severe proteinuria, and has been reported to be effective (5-8). However, steroid pulse therapy may cause rapid progression of renal dysfunction in some patients, because of adverse reactions such as increased blood pressure and exacerbated blood coagulation (9-11). Kobayashi et al (8) investigated this point in groups of patients given steroid therapy or untreated, and reported that steroid therapy is likely effective in progressive IgA nephropathy patients with proteinuria of 1-2 g/day and in renal function maintained with a creatinine clearance of at least $70 \mathrm{ml} / \mathrm{min}$. The present patient had relatively mild proteinuria and her renal functions were 

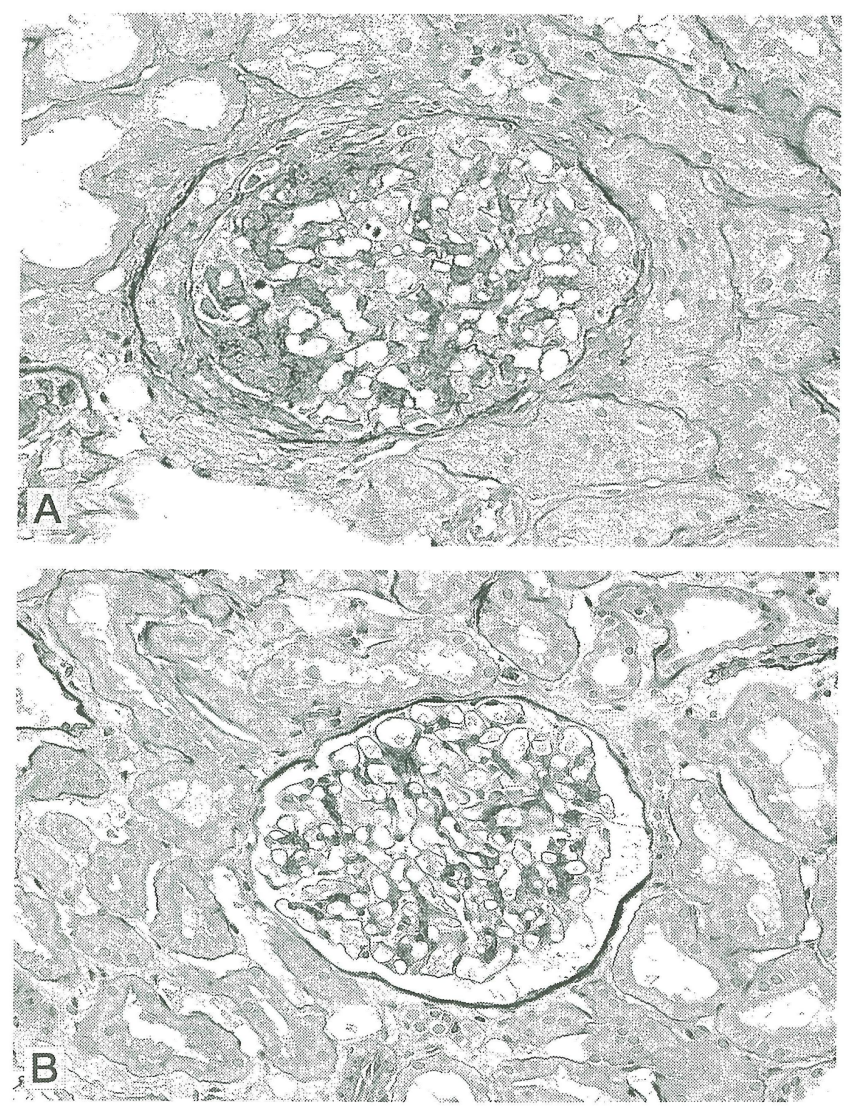

Figure 1. Light micrograph of renal biopsy tissue (PAS stain, $\times 280$ ). A) At the first renal biopsy, segmental sclerosis and fusion with Bowman's capsule, and fibro-cellular crescents are present. B) At the third renal biopsy after steroid mini-pulse therapy, only slight proliferation of mesangial cells and matrix are present.

within the normal range, but histological examination had found small crescents in $20 \%$ of the glomeruli which appeared to be active (12). The small crescents may be associated with an unfavorable prognosis (13). The immunohistochemical study, using frozen specimens, found a distribution of IL- 6 in the glomeruli, but no PDGF-A or -B. Recent immunohistochemical and other studies have suggested that cytokines such as IL6 and PDGF are involved in the progression and exacerbation of IgA nephropathy (14-16). Our findings in the present patient indicated that progression and exacerbation of glomerular lesions had occurred. Therefore, early steroid therapy was undertaken, resulting in no increases in proteinuria, aggravation of renal function or progression of histological lesions, and the apparent improvement in her condition. Following steroid therapy, the distribution of IL-6 in the glomeruli disappeared, suggesting that steroid therapy is indicated for patients with IgA nephropathy harboring active lesions. The expression of IL-6 mRNA is inhibited by glucocorticoid (17), thus studies on the localization of cytokines in the glomeruli during renal biopsy may be useful as an index of the therapeutic effect. Recently,
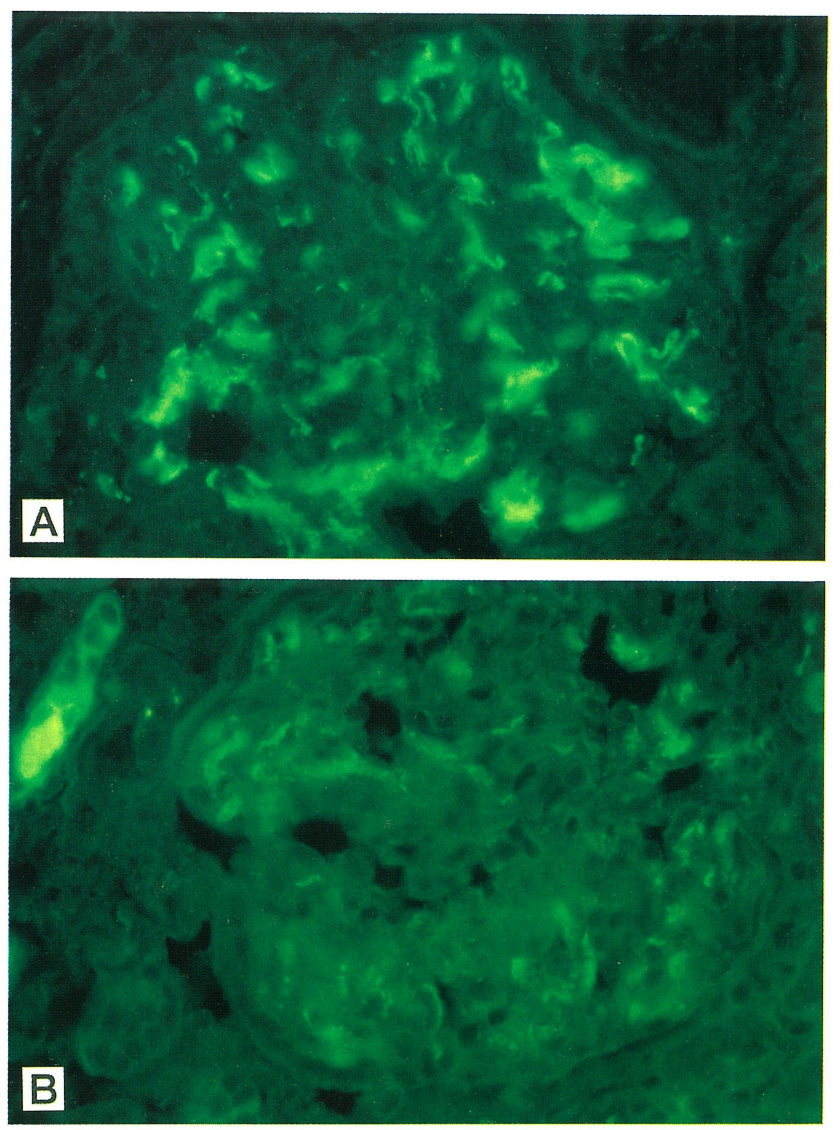

Figure 2. Fluorescent antibody staining $(\times 100)$. A) At the first renal biopsy, IgA deposits are present, mainly in the mesangial region. B) After steroid mini-pulse therapy, IgA deposits are few and weakly stained.

Dohi et al (18) suggested that the measurement of urinary IL6 activity is a helpful method for monitoring the progression of IgA nephropathy and it can be used as an alternative to renal biopsy. Further study is required in more patients to evaluate the potential of measurement of urinary IL-6 activity as a clinical indicator.

\section{References}

1) Berger J, Hinglais N. Les depots intercapillaires d'IgA-IgG. J Urol Nephrol 74: 694, 1968.

2) D'Amico G. Influence of clinical and histological features on actuarial renal survival in adult patients with idiopathic IgA nephropathy, membranous nephropathy, and membranoproliferative glomerulonephritis: survey of the recent literature. Am J Kidney Dis 20: 315, 1992.

3) Chan MK, Kwan SYL, Chan KW, Yeung CK. Controlled trial of antiplatelet agents in mesangial IgA glomerulonephritis. Am J Kidney Dis 9: 417, 1987.

4) Lai KN, Lai FM, Li PKT, Vallance-Owen J. Cyclosporin treatment of IgA nephropathy: a short term controlled trial. Br Med J 295: 1165, 1987.

5) Mustonen J, Pasternack A, Rantala I. The nephrotic syndrome in IgA glomerulonephritis: response to corticosteroid therapy. Clin Nephrol 20: 

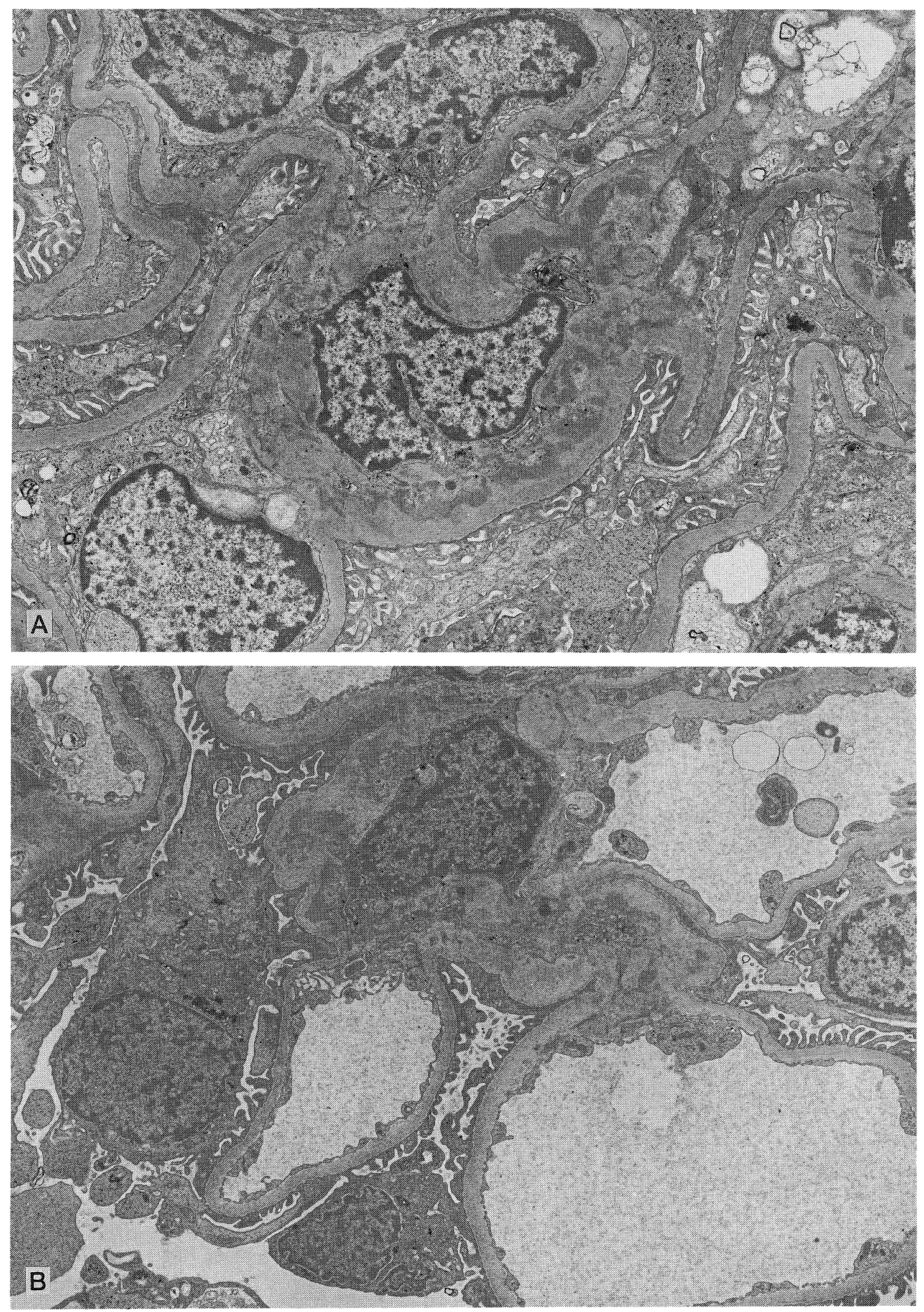

Figure 3. Electron micrographs $(A . \times 3,000 ; B, \times 2,500)$. A) At the first admission, electron dense deposits were present in the mesangial region. B) At the third admission, only mild electron dense deposits were present in the mesangial region. 

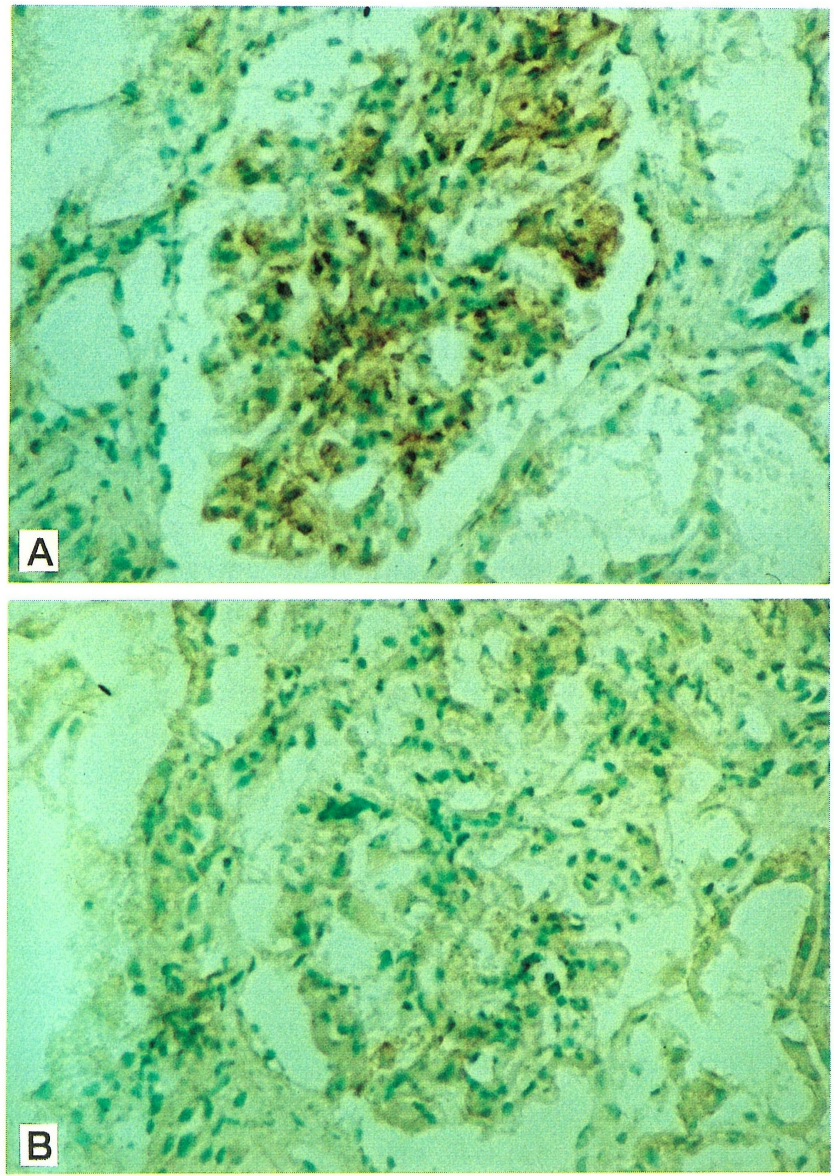

Figure 4. Immunohistochemical findings $(\times 300)$. A) At the first admission, diffuse distribution of IL- 6 was found in the mesangial region. B) After steroid mini-pulse therapy, almost all the IL-6 distribution had disappeared.
$172,1983$.

6) Lai $\mathrm{KN}$, Lai FN, Ho CP, Chan KW. Corticosteroid therapy in $\operatorname{IgA}$ nephropathy with nephrotic syndrome: a long-term controlled trial. Clin Nephrol 26: 174, 1986.

7) Waldo FB, Alexander R, Wyatt RJ, Kohaut EC. Alternate-day prednisone therapy in children with IgA-associated nephritis. Am J Kidney Dis 13: $55,1989$.

8) Kobayashi Y, Hiki Y, Fujii K, Kurokawa A, Tateno S. Moderately proteinuric IgA nephropathy: prognostic prediction of individual clinical courses and steroid therapy in progressive cases. Nephron 53: 250, 1989.

9) Welch TR, McAdams AJ, Berry A. Rapidly progressive IgA nephropathy. Am J Dis Child 142: 789, 1988.

10) Sakemi T, Yamaguchi M, Fujimi S, Nagano Y, Uchida M. Effects of the methylprednisolone pulse therapy on renal function. Am J Nephrol 11: 48, 1991.

11) Sakemi T, Fujimoto $S$, Fujimi $S$, Yamamoto $Y$, Etoh $T$, Yamaguchi $M$. Difference between renal failure associated with methylprednisolone pulse therapy and deterioration of renal function unrelated to methylprednisolone therapy. Am J Nephrol 13: 132, 1993.

12) Abe $T$, Kida $H$, Yoshimura $M$, et al. Participation of extracapillary lesion (ECL) in progression of nephropathy. Clin Nephrol 25: 37, 1986.

13) Hotta O, Taguma Y, Kurosawa K, Sudo K, Suzuki K, Horigome I. Predictive value of small crescents in IgA nephropathy: analysis of four patients showing a deteriorated renal function during a long follow-up period. Clin Nephrol 40: 125, 1993.

14) Fukatsu A, Matsuo $S$, Tamai $H$, Sakamoto $N$, Matsuda $T$, Hirano $T$. Distribution of interleukin-6 in normal and diseased human kidney. Lab Invest 65: 61, 1991.

15) Coleman DL, Ruef C. Interleukin-6: an autocrine regulator of mesangial cell growth. Kidney Int 41: 604, 1992.

16) Johnson R, Iida H, Yoshimura A, Floege J, Bowen-Pope DF. Plateletderived growth factor: a potentially important cytokine in glomerular disease. Kidney Int 41: 590, 1992.

17) Helfgott DC, May LT, Sthoeger Z, Tamm I, Sehgal PB. Bacterial lipopolysaccharide (endotoxin) enhances expression and secretion of $\beta_{2}$ interferon by human fibroblasts. J Exp Med 166: 1300, 1987.

18) Dohi K, Iwano M, Muraguchi A, et al. The prognostic significance of urinary interleukin 6 in IgA nephropathy. Clin Nephrol 35: 1, 1991. 